\title{
Characterization of Various Color Parameters (Anthocyanins and Flavonols) of Leaves and Flowers in Different Autochthonous Genotypes of Cyclamen purpurascens
}

\author{
Gregor Osterc ${ }^{1}$, Maja Mikulic Petkovsek, and Franci Stampar \\ Department of Agronomy, Biotechnical Faculty, University of Ljubljana, Jamnikarjeva 101, \\ Ljubljana SI-1000, Slovenia \\ Biljana Kiprovski \\ Institute of Field and Vegetable Crops, University of Novi Sad, Novi Sad 21000, Serbia \\ Blanka Ravnjak and Joze Bavcon \\ Department of Biology, University of Ljubljana Botanical Garden, Ižanska cesta 15, Ljubljana \\ SI-1000, Slovenia
}

\begin{abstract}
AdDITIONAL INDEX wORDs. anthocyanin content, color characteristics, flavonol content, foliage marbling
Abstract. Common cyclamen (Cyclamen pururascens Mill.) is a very interesting species not only for various breeding programs but also as an ornamental plant. The plants possess interesting floral and foliage characteristics, nice fragrances, and a very useful flavonol profile. The last is very important from the point of view of protecting against diseases and physiological disorders. Twenty-two different genotypes originating from different regions in Slovenia were analyzed in detail, based on their floral and foliage characteristics. Anthocyanin and flavonol contents were determined using high-performance liquid chromatography (HPLC)-photodiode array-mass spectrometry (MS). Color characteristics were colorimetrically evaluated separately for petals and leaves. In terms of color measurements, significant differences among the sites of origin were shown with parameters $a^{*}$ and $L^{*}$ when petals were analyzed, and with parameter $a^{*}$ when leaves were analyzed. The $\mathrm{pH}$ of petal sap stayed within the acid range, ranging from 3.96 to 4.82. Five different anthocyanins (malvidin-3,5-diglucoside, cyanidin-3-neohesperidoside, delphinidin-3-glucoside, delphinidin-3,5-diglucoside, and delphinidine-3-rutinoside) were analyzed in flowers, and this is the first report of delphinidin metabolites naturally present in common cyclamen genotypes. In relation to plant leaves, malvidin-3,5-diglucoside, malvidin-3-rutinoside, malvidin-3-glucoside, cyanidin-3-neohesperidoside, and peonidin-3-neohesperidoside were measured. Fifteen different flavonols were determined in common cyclamen flowers and 10 different flavonols in common cyclamen leaves. Various glycosides of quercetin, myricetin, and kaempferol were analyzed, as well as isorhamnetin-3-rutinoside, laricitin-3-rutinoside, and neohesperidin. The floral and foliage characteristics of the genotypes (physical and chemical) were mainly affected by the environmental conditions of the locality of origin of the genotypes (annual disposition of temperature and precipitation, structure of the soil, etc.).
\end{abstract}

Common cyclamen is a very important part of Slovenian flora. The plants are widespread in forests, on forest borders, and on meadows all over the country, from the coast to higher altitudes (Bavcon, 2009; Slovák et al., 2012). The great impact of common cyclamen is also closely connected with its floral characteristics. Common cyclamen usually develops flowers together with leaves (Bavcon, 2009, 2013; Grey-Wilson, 1988, 2002; Hildebrand, 1898; Mathew, 2013). However, as reported by Bavcon (2009), flowers very often develop in Slovenian climate before the leaves appear. Individuals have flowers with relatively large pale pink to purple flowers with an intense fragrance. Ishizaka et al. (2002) explained this intense fragrance as a result of the formation of citronellol, cinnamic alcohol, and their esters. Common cyclamen develops a lot of

Received for publication 14 Dec. 2017. Accepted for publication 5 Feb. 2018. This work is a part of the Program Horticulture No. P4-0013-0481 granted by the Slovenian Research Agency.

${ }^{1}$ Corresponding author. E-mail: gregor.osterc@bf.uni-lj.si. flowers, usually between 10 and 15 , but sometimes even as many as 70 (Bavcon, 2009, 2013). They develop on floral scapes, which are between eight and 12 or even $18 \mathrm{~cm}$ long (Bavcon, 2009; Grey-Wilson, 1988, 2002); they can also develop from primordias of floral scapes. Cyclamens have many dormant primordia buds, which start to sprout if the main floral scape is damaged (Bavcon, 2009). The flower color of common cyclamen varies from pale washed-out pink to very deep rose pink or carmine; sometimes whitish flowers also appear, although pure white flowers are very rare (Bavcon, 2009, 2013; Bavcon and Ravnjak, 2015; Grey-Wilson, 1988, 2002; Mathew, 2013). The flower color is a result of anthocyanin formation in the flower petals and it depends on the $\mathrm{pH}$ of the petal sap and on the degree of irradiation. Common cyclamen, compared with persian cyclamen $(C$. persicum L.), which had been increasingly cultivated as pot plants in middle Europe during last decades, also has an important ornamental value in terms of different foliar characteristics. Populations of common cyclamen in Slovenia can be grouped into four different groups based on foliar differences: green, marbled, 
semisilvery, and silvery (Bavcon, 2009; Osterc et al., 2014). The color on the opposite side of their laminas varies from totally green to dark violet (Bavcon, 2009; Grimshaw, 1992; Osterc et al., 2014). Leaves of green and marbled genotypes contain high levels of various quercetin and myricetin compounds, as well as higher laricitrin and kaempferol levels than semisilvery and silvery genotypes. Isorhamnetin-3-rutinoside and neohesperidin concentrations prevail in marbled and silvery genotypes (Osterc et al., 2014).

We do not know a lot about anthocyanin formation in the flower petals of common cyclamen because of very weak knowledge about the anthocyanin metabolism in this species. We wanted to study in more detail the reasons for such a diverse color palette of flowers in common cyclamen.

The aim of this study was to analyze Slovenian genotypes of common cyclamen in more detail. We widened the analysis to additional genotypes and also included plant flowers, not only leaves. Great differences in color among genotypes, which are a very important aspect for the ornamental and breeding industry, are explained by specific combinations of different anthocyanins.

\section{Materials and Methods}

Plant material. The common cyclamen plants involved in this study were collected in situ from all over Slovenia. The collection of 22 different genotypes was started in 2001 (Bavcon, 2009; Osterc et al., 2014). These genotypes originated from five different Slovenian regions: west Slovenia (W), western border with Croatia (WB), southwest Slovenia (SW), southeast Slovenia (SE), and southeastern border with Croatia (SEB) (Table 1; Fig. 1). Some regions cover large areas, so they were divided into different localities to enable more precise analysis of data (Table 1). The sampled genotypes already differed strongly in terms of floral and foliage characteristics (color and marbling) (Fig. 2).

The plants were dug from the soil, stored in plastic bags, and moistened as necessary. Each bag was labeled with the name of the location and the collection date. The plants were transferred to the University Botanic Garden in Ljubljana, Slovenia (lat. $46^{\circ} 03^{\prime} 20^{\prime \prime} \mathrm{N}$, long. $14^{\circ} 30^{\prime} 30^{\prime \prime} \mathrm{E}$ ), where they were planted in $10 \times 10-\mathrm{cm}$ or $10 \times 15$-cm pots, depending on the tuber size. Each pot was provided with a label indicating the locality (location/site) and the collection date. The plants were planted in a mixture of garden-made leaf mold and compost. The pots were arranged on a perforated foil to prevent weed growth and watered and shaded when necessary with a shadecloth (the degree of shade was between $30 \%$ and $50 \%$ ), and they were not given extra protection during the winter.

Leaves and flowers for polyphenol and anthocyanin identification were sampled in Sept. 2014. Three leaves and all developed flowers were removed from each plant, stored in plastic bags, and immediately ( $10 \mathrm{~min}$ by automobile) transported to the laboratory facility in a cooling bag. Leaf and flower stems were removed and discarded, and only leaf laminas and flowers were frozen at $-20{ }^{\circ} \mathrm{C}$. The color of leaves and flowers was measured before the material was frozen.

Environmental conditions. The experimental year 2014 was very specific in terms of environmental conditions. The period between July and December of a year is particularly
Table 1. Overview of genotypes of Cyclamen purpurascens used in the experiment, originating from different regions in Slovenia.

\begin{tabular}{lcc}
\hline Region $^{\mathrm{z}}$ & Localities (no.) & Genotypes (no.) \\
\hline W & 3 & 5 \\
WB & 3 & 10 \\
SW & 2 & 2 \\
SE & 2 & 2 \\
SEB & 2 & 3 \\
Total & 12 & 22
\end{tabular}

${ }^{\mathrm{z}} \mathrm{W}=$ west Slovenia; $\mathrm{WB}=$ western border with Croatia; $\mathrm{SW}=$ southwest Slovenia; SE = southeast Slovenia; SEB = southeastern border with Croatia.

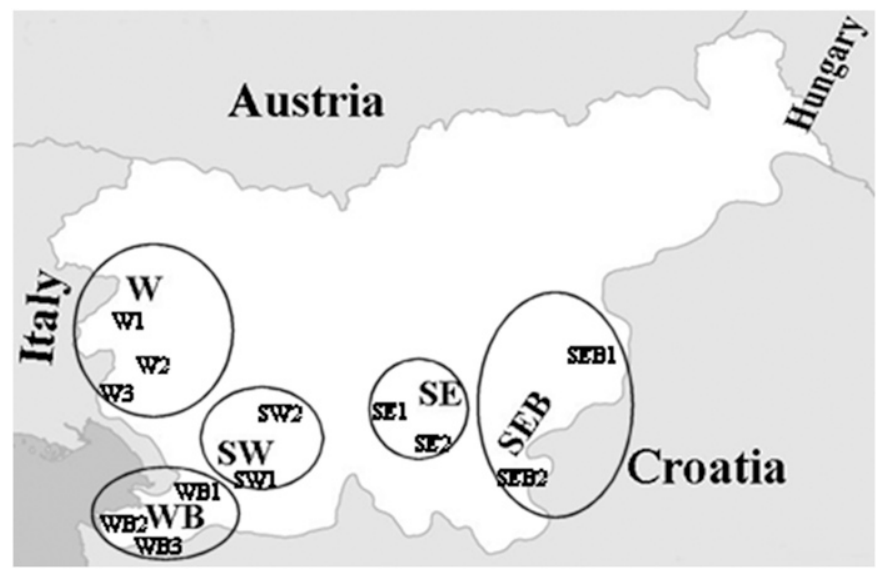

Fig. 1. Position of the regions in Slovenia in which the Cyclamen purpurascens genotypes were collected. $\mathrm{W}=$ west Slovenia; $\mathrm{WB}=$ western border with Croatia; SW = southwest Slovenia; $\mathrm{SE}=$ southeast Slovenia; $\mathrm{SEB}=$ southeastern border with Croatia.

important for cyclamen development. The irradiation rate was stronger (data not shown) and temperatures were higher than the long-term average during these months in this year. The amount of precipitation was much higher in 2014 than the long-term average, especially in autumn (November) (Figs. 3 and 4) (Statistical Office of the Republic of Slovenia, 2016).

Color measurements. Leaf (measured on the underside of the lamina) and petal color were measured with a portable colorimeter (CR-10 Chroma; Minolta, Osaka, Japan) with C illuminant. The colorimeter was calibrated with a white standard calibration plate before use. In the CIE $L^{*} a^{*} b^{*}$ system of color representation, the $L^{*}$ value corresponds to a dark-bright scale and represents the relative lightness in a range from 0 to $100(0=$ black, $100=$ white $)$. Color parameters $a^{*}$ and $b^{*}$ extend from -60 to $60 ; a^{*}$ negative is for green, $a^{*}$ positive is for red, whereas $b^{*}$ negative is for blue and $b^{*}$ positive is for yellow. The hue angle $\left(\mathrm{h}^{\circ}\right)$ is expressed in degrees from 0 to 360 , whereby $0^{\circ}=\mathrm{red}, 90^{\circ}=$ yellow, $180^{\circ}=$ green, and $270^{\circ}=$ blue. Color was measured in the middle of each leaf and petal to ensure equal measurement conditions.

Extraction of PHENOLIC Compounds. For flavonols and anthocyanin quantification, the leaf laminas and flowers were ground to a fine powder with liquid nitrogen. Then $0.5 \mathrm{~g}$ of powder was extracted with $2 \mathrm{~mL}$ methanol containing $3 \%(\mathrm{v} / \mathrm{v})$ formic acid and 1\%(w/v) 2,6-di-tert-butyl-4-methylphenol 

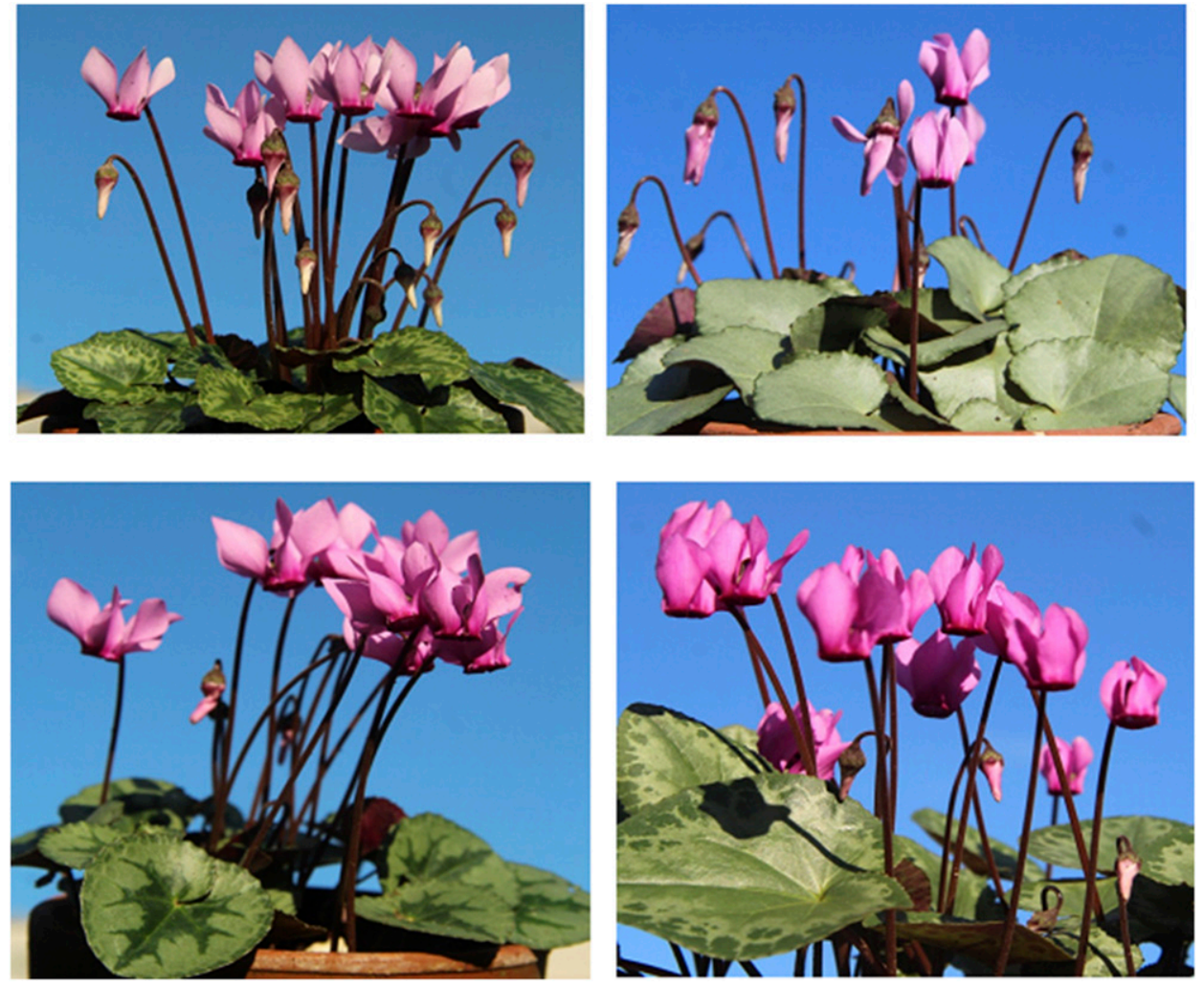

Fig. 2. The most pronounced characteristics of Cyclamen purpurascens genotypes are significant variations in floral and foliage characteristics (color and marbling).

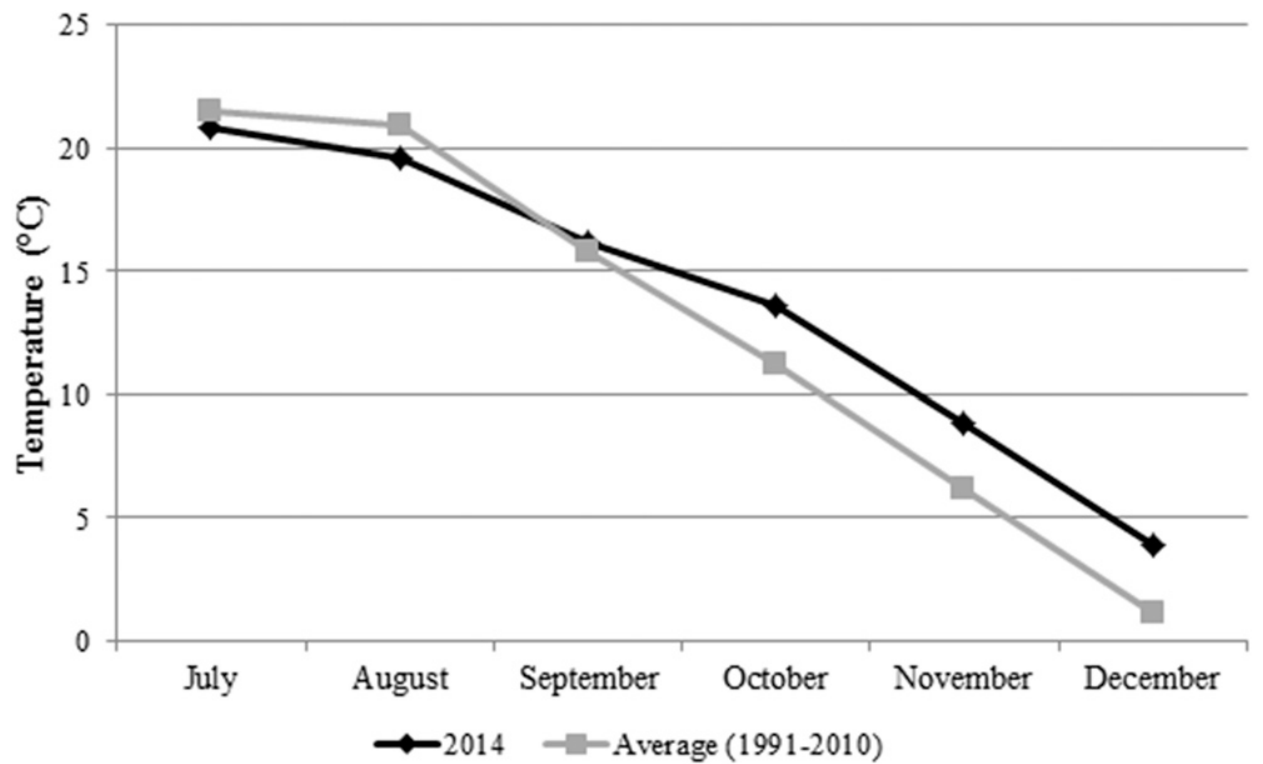

Fig. 3. Comparison of average temperatures during the part of 2014 with the most intensive Cyclamen purpurascens development and the long-term annual average temperatures (1991-2010) for Ljubljana, Slovenia.

(BHT) in an ultrasonic bath for $1 \mathrm{~h}$. The samples were centrifuged for $7 \mathrm{~min}$ at $12,000 \mathrm{~g}_{\mathrm{n}}$. Supernatant was filtered through a polyamide filter (Chromafil AO-20/25; MachereyNagel, Düren, Germany) and transferred to a vial before injection into a HPLC system (Thermo Fisher Scientific, Waltham, MA).

DETERMination OF INDIVIDUAL PHENOLIC COMPOUNDS USING HPLC-DIODE ARRAY DETECTIONELECTROSPRAY IONIZATION-MS (DAD-ESI-MS ${ }^{\mathrm{N}}$ ) ANALYSIS. Phenolic compounds were analyzed on a Thermo Finnigan Surveyor HPLC system (Thermo Fisher Scientific) with DAD at $350 \mathrm{~nm}$ (flavonols) and $530 \mathrm{~nm}$ (anthocyanins). The spectra of the compounds were recorded between 200 and $600 \mathrm{~nm}$. The column was a Gemini C18 $(150 \times 4.6 \mathrm{~mm}$, $3 \mu \mathrm{m}$; Phenomenex, Torrance, $\mathrm{CA})$ operated at $25^{\circ} \mathrm{C}$. The elution solvents were aqueous $0.1 \%$ formic acid in double-distilled water (A) and $0.1 \%$ formic acid in acetonitrile (B). The samples were eluted according to a linear gradient from $5 \%$ to $20 \% \mathrm{~B}$ in the first $15 \mathrm{~min}$, followed by a linear gradient from $20 \%$ to $30 \%$ B for $5 \mathrm{~min}$, then an isocratic mixture for $5 \mathrm{~min}$, followed by a linear gradient from $30 \%$ to $90 \%$ B for $5 \mathrm{~min}$, and finally an isocratic mixture for $15 \mathrm{~min}$ before returning to the initial conditions (Wang et al., 2002). The injection amount was $20 \mu \mathrm{L}$ and flow rate was $0.6 \mathrm{~mL} \cdot \mathrm{min}^{-1}$.

All phenolic compounds were identified by a HPLC-Finnigan MS detector and an LCQ Deca XP MAX (Thermo Fisher Scientific) instrument with ESI operating in positive (for anthocyanins) and negative (other flavonol groups) ion modes. The analyses were carried out using full scan data-dependent $\mathrm{MS}^{\mathrm{n}}$ scanning from $\mathrm{m} / \mathrm{z} 110$ to 1500. Column and chromatographic conditions were identical to those used for HPLC-DAD analysis. The injection volume was $10 \mu \mathrm{L}$ and the flow rate was maintained at 0.6 $\mathrm{mL} \cdot \mathrm{min}^{-1}$. The capillary temperature was $250{ }^{\circ} \mathrm{C}$, the sheath gas and auxiliary gas were 60 and 15 units, respectively, the source voltage was $3 \mathrm{kV}$ for negative ionization and $4 \mathrm{kV}$ for positive ionization, and normalized collision energy was between $20 \%$ and $35 \%$. Spectral data were elaborated using Excalibur software (Thermo Fisher Scientific). Identification of the compounds was confirmed by comparing retention times and their spectra and by adding a standard solution to the sample and by fragmentation (Osterc et al., 2014).

PH MEASUREMENTS OF THE PETAL SAP. Twenty milligrams of powder of flower petals, which had been previously prepared 


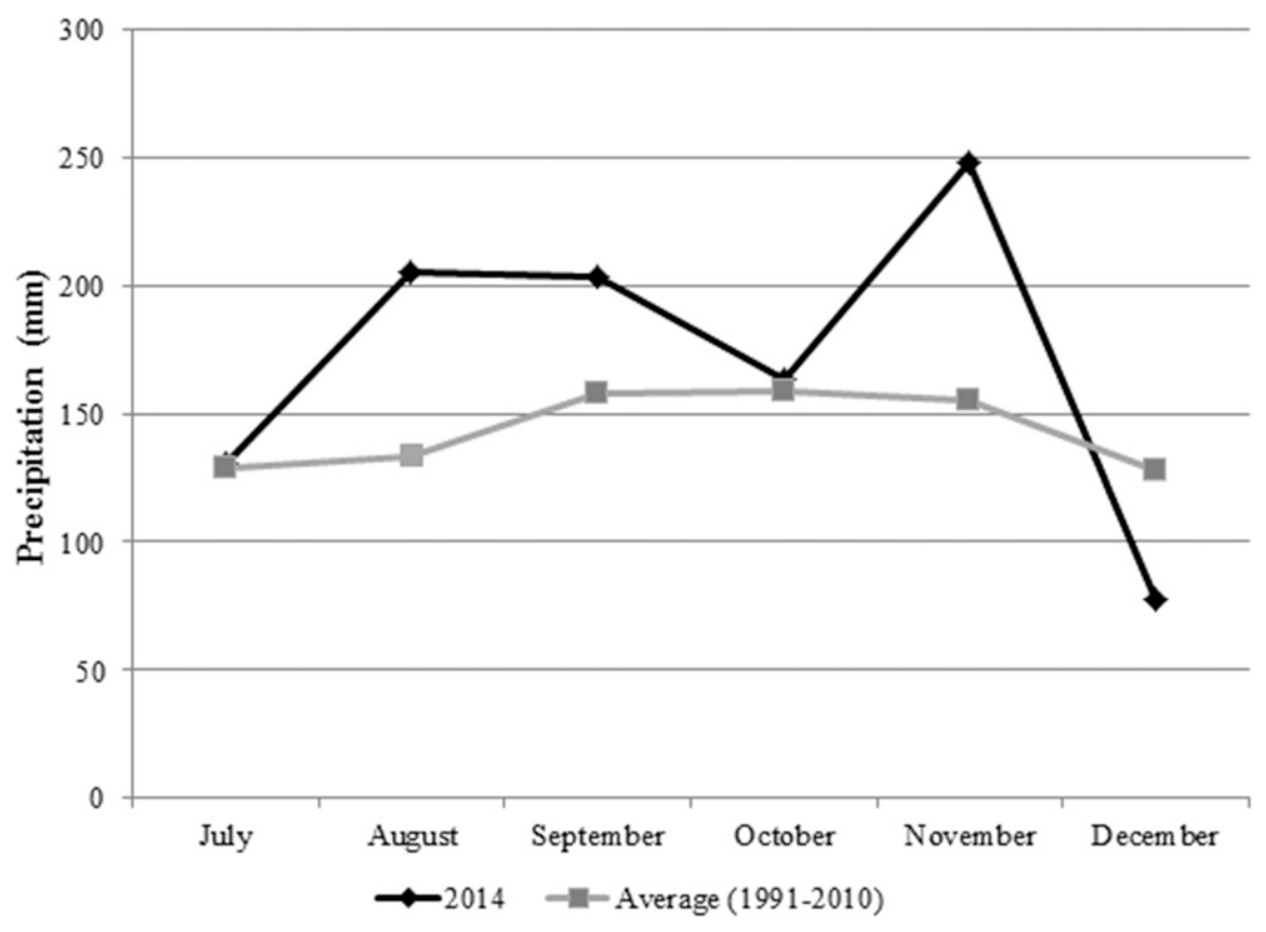

Fig. 4. Comparison of average precipitation during the part of 2014 with the most intensive Cyclamen purpurascens development in Ljubljana and the average of long-term annual precipitation (1991-2010) for Slovenia.

for anthocyanin and flavonol extraction with liquid nitrogen, was extracted with $20 \mathrm{~mL}$ of $0.01 \mathrm{M} \mathrm{CaCl}_{2}$ solution for $2 \mathrm{~h} . \mathrm{pH}$ was then measured in the solution using a $\mathrm{pH}$ meter $(\mathrm{pH} 720$, WTW Series; Mettler Toledo, Columbus, OH).

Chemicals. The following standards were used for quantification of phenolic compounds: rutin (quercetin-3-O-rutinoside) and peonidin-3-O-glucoside from Sigma-Aldrich (St. Louis, $\mathrm{MO}$ ), quercetin-3-O-galactoside and cyanidin-3-O-galactoside from Fluka Chemie (Buchs, Switzerland), isorhamnetin-3-Oglucoside and malvidin-3-O-glucoside from Extrasynthese (Genay Cedex, France), and myricetin-3-O-rhamnoside from Apin Chemicals (Abingdon, UK). Methanol for the extraction of phenolics was acquired from Sigma-Aldrich. The chemicals for the mobile phases were HPLC-MS grade acetonitrile and formic acid from Fluka Chemie. Water for the mobile phase was double distilled and purified with the Milli-Q system (Millipore, Bedford, MA).

Statistical Evaluation. The experiment was set as a single-factor experiment, with the region of genotype origin as the factor. For all measurements (color measurements, $\mathrm{pH}$ value of the cell sap, and chemical analyses), three welldeveloped leaves and flowers from one plant (one genotype) were used as replications, and end values were average values from these replications. One-way analysis of variance was performed for statistical analysis. Statistically significant differences were tested with the Duncan test at a 0.95 confidence level. Statistical analysis was not possible in the case of flowers, partly because of insufficient material for the analysis (plants often developed only one flower or no flowers at all). To classify the clones according to their origin and to discover natural groupings of samples, principal component analysis and cluster analysis (with unweighted pair-group average analysis using Euclidean distance) were additionally carried out. All statistical analyses were performed using STATISTICA (version 13 for Windows; Dell Software, Aliso Viejo, CA).

\section{Results}

Color measurements. The colors of petals and leaves were separately evaluated colorimetrically. Values of parameter $a^{*}$ of the petals ranged between 13.13 and 49.67 in relation to different regions, and the differences were significant. Values of parameter $b^{*}$ remained under 0 , except in the case of origin region $\mathrm{W} 3$ (Tables 1 and 2). The values of parameter $L^{*}$ ranged between 24.87 and 54.07, and the differences were significant. The $\mathrm{pH}$ value of the petal sap of plants from all regions remained within the acid range, ranging from 3.96 to 4.82 (Table 2). Values of parameter $a^{*}$ when the leaves were measured were generally lower than when the petals were measured, ranging from 2.27 to 17.10 . The differences were significant. The values of parameter $b^{*}$ were above 0 , ranging from 0.40 to 13.53 when the color of the leaves was measured, but the differences were not significant. The values of parameter $L^{*}$ were only slightly lower in the case of leaves than with petals and ranged from 28.39 to 42.83 (Table 3).

Anthocyanins in flowers. It was possible to detect five different anthocyanins in cyclamen flowers: malvidin-3,5-diglucoside, cyanidin-3-neohesperidoside, delphinidin-3-glucoside, delphinidin-3,5-diglucoside, and delphinidin-3-rutinoside (Table 4). The substance that tended to be present at the highest concentration was malvidin-3,5-diglucoside; flowers with anthocyanins from the delphinidin group contained mostly delphinidin-3-glucoside. Genotypes from west Slovenia, especially the third genotype, tended to have higher anthocyanin concentrations in their flowers than did genotypes from other parts of Slovenia (Table 5).

Anthocyanins in Leaves. Cyclamen leaves contained five different anthocyanins: malvidin-3,5-diglucoside, malvidin-3rutinoside, malvidin-3-glucoside, cyanidin-3-neohesperidoside, and peonidin-3- neohesperidoside (Table 4). The substance that was mostly present was malvidin-3,5-diglucoside, followed by malvidin-3-rutinoside and malvidin-3-glucoside. The statistically highest concentrations of malvidin-3,5-diglucoside, malvidin-3-glucoside, and malvidin-3-rutinoside were measured in the leaves of genotypes originating from the west Slovenian border with Croatia and from southwest Slovenia (Table 6).

Flavonols in FlOWERs. Flowers of common cyclamen genotypes were very rich in various flavonol compounds. We were able to determine various compounds from different phenolic groups: derivates of myricetin, quercetin (Tables 7 and 8), and kaempferol (Tables 7 and 9). Among quercetin derivates, the highest concentrations of quercetin-3-rutinoside were measured, with values between 1389.81 and 2637.45 
Table 2. Parameters of the color measurement of flowers and $\mathrm{pH}$ value of the petal cell sap of different Slovenian Cyclamen purpurascens genotypes $(n=3)$.

\begin{tabular}{|c|c|c|c|c|c|c|}
\hline \multirow{2}{*}{$\begin{array}{l}\text { Genotype } \\
\text { origin }^{z}\end{array}$} & $a^{*}$ & $b^{*}$ & $L^{*}$ & $C^{*}$ & $\mathrm{~h}^{\circ}$ & $\overline{\mathrm{pH}}$ \\
\hline & \multicolumn{6}{|c|}{$($ Mean $\pm \mathrm{SD})$} \\
\hline $\mathrm{W} 1$ & $31.55 \pm 11.14 b^{y}$ & $-5.69 \pm 16.06 \mathrm{NS}$ & $36.75 \pm 3.51 \mathrm{ab}$ & $35.73 \pm 9.91 \mathrm{abcd}$ & $264.81 \pm 141.67 \mathrm{NS}$ & 4.82 \\
\hline W2 & $49.67 \pm 12.44 \mathrm{~d}$ & $-17.70 \pm 4.33 \mathrm{NS}$ & $34.70 \pm 11.79 \mathrm{ab}$ & $53.13 \pm 10.64 \mathrm{~d}$ & $339.40 \pm 7.98 \mathrm{NS}$ & 4.48 \\
\hline WB1 & $28.60 \pm 7.61 \mathrm{abc}$ & $-6.66 \pm 8.82 \mathrm{NS}$ & $37.13 \pm 7.16 \mathrm{ab}$ & $30.56 \pm 7.19 \mathrm{abc}$ & $270.10 \pm 140.56 \mathrm{NS}$ & 4.71 \\
\hline WB2 & $13.13 \pm 4.40 \mathrm{a}$ & $-2.30 \pm 10.20 \mathrm{NS}$ & $54.07 \pm 3.18 \mathrm{c}$ & $15.90 \pm 3.10 \mathrm{a}$ & $234.70 \pm 165.47 \mathrm{NS}$ & 4.65 \\
\hline WB3 & $31.02 \pm 14.74 \mathrm{bc}$ & $-14.00 \pm 15.73 \mathrm{NS}$ & $40.89 \pm 10.09 b$ & $36.44 \pm 16.92 \mathrm{bcd}$ & $295.23 \pm 99.77 \mathrm{NS}$ & 4.45 \\
\hline SW2 & $31.80 \pm 8.03 \mathrm{bc}$ & $-13.23 \pm 6.09 \mathrm{NS}$ & $39.57 \pm 7.58 \mathrm{~b}$ & $34.93 \pm 6.85 \mathrm{abcd}$ & $336.70 \pm 11.60 \mathrm{NS}$ & 4.57 \\
\hline SE1 & $41.80 \pm 3.54 \mathrm{~cd}$ & $-19.23 \pm 2.44 \mathrm{NS}$ & $36.77 \pm 5.84 \mathrm{ab}$ & $46.07 \pm 3.76 \mathrm{~cd}$ & $335.30 \pm 2.61 \mathrm{NS}$ & 4.70 \\
\hline SE2 & $18.70 \pm 7.46 a b$ & $-3.83 \pm 10.33 \mathrm{NS}$ & $34.90 \pm 2.86 \mathrm{ab}$ & $20.53 \pm 8.80 \mathrm{ab}$ & $236.90 \pm 182.95 \mathrm{NS}$ & 4.29 \\
\hline SEB1 & $26.32 \pm 6.92 \mathrm{abc}$ & $-8.65 \pm 10.25 \mathrm{NS}$ & $33.43 \pm 3.53 \mathrm{ab}$ & $28.70 \pm 9.27 \mathrm{abc}$ & $226.13 \pm 170.55 \mathrm{NS}$ & 3.96 \\
\hline SEB2 & $17.60 \pm 3.08 \mathrm{ab}$ & $-7.57 \pm 0.46 \mathrm{NS}$ & $42.03 \pm 13.71 \mathrm{~b}$ & $19.17 \pm 2.90 \mathrm{ab}$ & $336.40 \pm 3.12 \mathrm{NS}$ & 4.34 \\
\hline
\end{tabular}

${ }^{\mathrm{z}} \mathrm{W}=$ west Slovenia; $\mathrm{WB}=$ western border with Croatia; $\mathrm{SW}=$ southwest Slovenia; $\mathrm{SE}=$ southeast Slovenia; SEB = southeastern border with Croatia; $a^{*}=$ bluish-green/red-purple hue; $b^{*}=$ yellow/blue hue; $L^{*}=$ lightness; $C^{*}=$ chroma; $\mathrm{h}^{\circ}=$ hue angle.

${ }^{\mathrm{y}}$ Different letters $(\mathrm{a}-\mathrm{d})$ within columns show statistically significant differences in each parameter among different genotype origin by Duncan test at $P \leq 0.05$; NS $=$ not significant.

Table 3. Parameters of the color measurement of leaves of different Slovenian Cyclamen purpurascens genotypes $(n=3)$.

\begin{tabular}{|c|c|c|c|c|c|}
\hline \multirow{2}{*}{$\begin{array}{l}\text { Genotype } \\
\text { origin }^{z}\end{array}$} & $a^{*}$ & $b^{*}$ & $L^{*}$ & $C^{*}$ & $\mathrm{~h}^{\circ}$ \\
\hline & \multicolumn{5}{|c|}{$($ Mean \pm SD $)$} \\
\hline $\mathrm{W} 1$ & $15.23 \pm 3.12 \mathrm{c}^{\mathrm{y}}$ & $3.23 \pm 2.80 \mathrm{NS}$ & $29.01 \pm 3.96 \mathrm{a}$ & $15.89 \pm 2.47 \mathrm{bc}$ & $53.24 \pm 115.22 \mathrm{NS}$ \\
\hline W2 & $11.83 \pm 2.59 \mathrm{bc}$ & $7.47 \pm 2.90 \mathrm{NS}$ & $32.83 \pm 2.49 \mathrm{a}$ & $14.30 \pm 1.01 \mathrm{bc}$ & $32.63 \pm 14.87 \mathrm{NS}$ \\
\hline WB1 & $14.40 \pm 4.96 \mathrm{c}$ & $2.01 \pm 1.20 \mathrm{NS}$ & $28.39 \pm 2.74 \mathrm{a}$ & $14.67 \pm 4.68 \mathrm{bc}$ & $51.01 \pm 116.33 \mathrm{NS}$ \\
\hline WB2 & $16.97 \pm 4.80 \mathrm{c}$ & $2.03 \pm 5.39 \mathrm{NS}$ & $34.40 \pm 3.00 \mathrm{ab}$ & $17.80 \pm 3.73 \mathrm{c}$ & $129.53 \pm 194.51 \mathrm{NS}$ \\
\hline WB3 & $12.14 \pm 8.15 \mathrm{bc}$ & $5.58 \pm 7.70 \mathrm{NS}$ & $33.41 \pm 8.32 \mathrm{a}$ & $17.07 \pm 2.47 \mathrm{c}$ & $122.66 \pm 148.11 \mathrm{NS}$ \\
\hline SW2 & $13.93 \pm 1.71 \mathrm{bc}$ & $2.67 \pm 1.56 \mathrm{NS}$ & $29.90 \pm 1.78 \mathrm{a}$ & $14.23 \pm 1.44 \mathrm{bc}$ & $11.17 \pm 7.07 \mathrm{NS}$ \\
\hline SE1 & $16.10 \pm 2.61 \mathrm{c}$ & $2.90 \pm 2.29 \mathrm{NS}$ & $28.93 \pm 1.16 \mathrm{a}$ & $16.50 \pm 2.25 b c$ & $11.07 \pm 9.26 \mathrm{NS}$ \\
\hline SE2 & $2.27 \pm 6.45 \mathrm{a}$ & $10.37 \pm 2.44 \mathrm{NS}$ & $31.30 \pm 2.85 \mathrm{a}$ & $12.00 \pm 0.52 \mathrm{ab}$ & $77.53 \pm 34.01 \mathrm{NS}$ \\
\hline SEB1 & $10.33 \pm 5.26 \mathrm{abc}$ & $5.20 \pm 4.31 \mathrm{NS}$ & $34.97 \pm 3.06 \mathrm{ab}$ & $12.88 \pm 2.77 \mathrm{bc}$ & $30.92 \pm 28.85 \mathrm{NS}$ \\
\hline SEB2 & $4.80 \pm 0.40 \mathrm{ab}$ & $6.90 \pm 0.95 \mathrm{NS}$ & $34.80 \pm 0.56 \mathrm{ab}$ & $8.37 \pm 0.71 \mathrm{a}$ & $54.80 \pm 5.056 \mathrm{NS}$ \\
\hline
\end{tabular}

$\overline{{ }^{\mathrm{z}} \mathrm{W}}=$ west Slovenia; $\mathrm{WB}=$ western border with Croatia; $\mathrm{SW}=$ southwest Slovenia; $\mathrm{SE}=$ southeast Slovenia; $\mathrm{SEB}=$ southeastern border with Croatia; $a^{*}=$ bluish-green/red-purple hue; $b^{*}=$ yellow/blue hue; $L^{*}=$ lightness; $C^{*}=$ chroma; $\mathrm{h}^{\circ}=$ hue angle.

${ }^{\mathrm{y}}$ Different letters $(\mathrm{a}-\mathrm{c})$ within columns show statistically significant differences in each parameter among different genotype origin by Duncan test at $P \leq 0.05$; NS $=$ not significant.

Table 4. List of anthocyanins identified in Cyclamen purpurascens leaves and flowers, standards used for calculations, and MS ${ }^{\mathrm{n}}$ specifications. $^{\mathrm{z}}$

\begin{tabular}{|c|c|c|c|c|c|}
\hline \multirow[b]{2}{*}{ Anthocyanin } & \multirow[b]{2}{*}[\mathrm{M}^{+}]{$(\mathrm{m} / z)^{\mathrm{z}}$} & \multirow[b]{2}{*}{$\operatorname{MS}^{2}\left[\mathbf{M}^{+}\right](m / z)$} & \multirow[b]{2}{*}{ Expressed in } & \multicolumn{2}{|c|}{ Analyzed in } \\
\hline & & & & Leaves & Flowers \\
\hline Malvidin-3,5-diglucoside & 655 & $493 / 331$ & Malvidin-3-glucoside & $\mathrm{X}$ & $\mathrm{X}$ \\
\hline Cyanidin-3-neohesperidoside & 595 & $449 / 287$ & Cyanidin-3-galactoside & $\mathrm{X}$ & $\mathrm{X}$ \\
\hline Malvidin-3-glucoside & 493 & 331 & Malvidin-3-glucoside & $\mathrm{X}$ & \\
\hline Delphinidin-3-glucoside & 465 & 303 & Delphinidine-3-glucoside & & $\mathrm{X}$ \\
\hline Delphinidin-3,5-diglucoside & 627 & $463 / 303$ & Delphinidine-3-glucoside & & $X$ \\
\hline Delphinidin-3-rutinoside & 611 & $465 / 303$ & Delphinidine-3-glucoside & & $X$ \\
\hline
\end{tabular}

${ }^{\mathrm{z}} \mathrm{M}^{+}(\mathrm{m} / \mathrm{z})=$ anthocyanins were obtained in the positive ion mode; $\mathrm{MS}^{2}=$ mass spectrometrometry to the second degree.

$\mu \mathrm{g} \cdot \mathrm{g}^{-1}$ fresh weight (FW). The concentrations of myricetin3-rutinoside and myricetin-3-rhamnoside were highest in the group of myricetin glycosides. Kaempferol-rhamnosyl and -dirhamnosyl hexoside from the group of kaempferol glycosides reached the highest concentrations in cyclamen flowers. Laricitin-3-rutinoside and isorhamnetin-3-rutinoside were also analyzed (Tables 7 and 9). The values of laricitin ranged between 43.17 and $106.02 \mu \mathrm{g} \cdot \mathrm{g}^{-1} \mathrm{FW}$

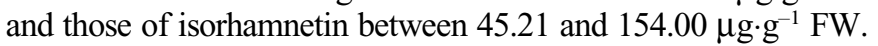

Flavonols in leaves. We were able to determine 10 different flavonol compounds in cyclamen leaves. They 
Table 5. Anthocyanin values in flowers of different Slovenian Cyclamen purpurascens genotypes $(n=3)$.

\begin{tabular}{|c|c|c|c|c|c|}
\hline \multirow{2}{*}{$\begin{array}{l}\text { Genotype } \\
\text { origin }^{z}\end{array}$} & $\begin{array}{l}\text { Malvinidin-3, } \\
\text { 5-diglucoside }\end{array}$ & $\begin{array}{l}\text { Cyanidin- } \\
\text { 3-neohesperidoside }\end{array}$ & $\begin{array}{l}\text { Delphinidin- } \\
\text { 3-glucoside }\end{array}$ & $\begin{array}{l}\text { Delphinidin- } \\
\text { 3,5-diglucoside }\end{array}$ & $\begin{array}{l}\text { Delphinidin- } \\
\text { rutinoside }\end{array}$ \\
\hline & \multicolumn{5}{|c|}{$\left[\text { Mean } \pm \text { SD }\left(\mu \mathrm{g} \cdot \mathrm{g}^{-1} \mathrm{FW}\right)\right]^{\mathrm{y}}$} \\
\hline W1 & $193.43 \pm 9.15$ & $1.49 \pm 0.25$ & $43.64 \pm 16.49$ & $6.93 \pm 2.62$ & $12.74 \pm 5.33$ \\
\hline W3 & 347.48 & 10.47 & 56.31 & 8.95 & 30.96 \\
\hline WB1 & $128.59 \pm 21.47$ & $0.80 \pm 0.54$ & $16.97 \pm 3.89$ & $2.70 \pm 0.62$ & $14.08 \pm 7.10$ \\
\hline WB2 & 116.92 & 0.70 & 23.25 & 3.69 & 14.51 \\
\hline SW1 & 193.47 & 5.04 & 55.72 & 8.85 & 8.37 \\
\hline SW2 & 119.32 & 6.73 & 35.31 & 5.61 & 30.45 \\
\hline SE1 & 280.86 & 2.23 & 41.68 & 6.62 & 36.91 \\
\hline SE2 & 144.84 & 0.10 & 11.80 & 1.88 & 4.91 \\
\hline SEB1 & $181.92 \pm 88.16$ & $4.65 \pm 6.16$ & $77.96 \pm 79.73$ & $12.39 \pm 12.67$ & $18.93 \pm 3.95$ \\
\hline SEB2 & 67.95 & 0.13 & 11.17 & 1.78 & 6.56 \\
\hline
\end{tabular}

${ }^{\mathrm{z}} \mathrm{W}=$ west Slovenia; $\mathrm{WB}=$ western border with Croatia; $\mathrm{SW}=$ southwest Slovenia; $\mathrm{SE}=$ southeast Slovenia; $\mathrm{SEB}=$ southeastern border with Croatia.

${ }^{\mathrm{y}}$ Statistical analysis was not possible if not enough material for the analysis (plants often developed only one flower) was available.

$\mathrm{FW}=$ fresh weight.

Table 6. Anthocyanin values in leaves of different Slovenian Cyclamen purpurascens genotypes $(n=3)$.

\begin{tabular}{|c|c|c|c|c|c|}
\hline \multirow{2}{*}{$\begin{array}{l}\text { Genotype } \\
\text { origin }^{z}\end{array}$} & $\begin{array}{l}\text { Malvinidin- } \\
\text { 3,5-diglucoside }\end{array}$ & $\begin{array}{c}\text { Cyanidin- } \\
\text { 3-neohesperidoside }\end{array}$ & $\begin{array}{c}\text { Peonidin- } \\
\text { 3-neohesperidoside }\end{array}$ & $\begin{array}{l}\text { Malvidin- } \\
\text { 3-glucoside }\end{array}$ & $\begin{array}{l}\text { Malvidin- } \\
\text { 3-rutinoside }\end{array}$ \\
\hline & \multicolumn{5}{|c|}{$\left[\text { Mean } \pm \text { sD }\left(\mu g \cdot g^{-1} F W\right)\right]^{y}$} \\
\hline W1 & $107.73 \pm 41.99 b^{y}$ & $3.17 \pm 1.47 \mathrm{NS}$ & $4.48 \pm 1.71 \mathrm{NS}$ & $48.37 \pm 18.49 \mathrm{NS}$ & $52.97 \pm 29.28 \mathrm{NS}$ \\
\hline W3 & $16.06 \pm 8.41 \mathrm{a}$ & $0.93 \pm 0.78 \mathrm{NS}$ & $0.59 \pm 0.21 \mathrm{NS}$ & $6.34 \pm 2.24 \mathrm{NS}$ & $4.72 \pm 1.95 \mathrm{NS}$ \\
\hline WB1 & $135.58 \pm 75.62 \mathrm{c}$ & $2.70 \pm 3.64 \mathrm{NS}$ & $1.22 \pm 1.48 \mathrm{NS}$ & $13.17 \pm 16.01 \mathrm{NS}$ & $51.08 \pm 62.21 \mathrm{NS}$ \\
\hline SW1 & $88.02 \pm 26.20 \mathrm{abc}$ & $4.88 \pm 3.75 \mathrm{NS}$ & $5.16 \pm 3.01 \mathrm{NS}$ & $55.70 \pm 32.48 \mathrm{NS}$ & $56.17 \pm 22.73 \mathrm{NS}$ \\
\hline SW2 & $109.12 \pm 22.52 \mathrm{bc}$ & $1.98 \pm 0.37 \mathrm{NS}$ & $2.43 \pm 0.66 \mathrm{NS}$ & $26.21 \pm 7.13 \mathrm{NS}$ & $24.96 \pm 7.68 \mathrm{NS}$ \\
\hline SE1 & $75.93 \pm 18.95 \mathrm{abc}$ & $2.54 \pm 0.97 \mathrm{NS}$ & $3.05 \pm 0.63 \mathrm{NS}$ & $32.98 \pm 6.83 \mathrm{NS}$ & $27.93 \pm 5.73 \mathrm{NS}$ \\
\hline SE2 & $39.33 \pm 6.43 \mathrm{ab}$ & $0.50 \pm 0.41 \mathrm{NS}$ & - & - & $29.10 \pm 7.61 \mathrm{NS}$ \\
\hline SEB1 & $81.20 \pm 62.12 \mathrm{abc}$ & $1.24 \pm 0.96 \mathrm{NS}$ & $1.35 \pm 0.77 \mathrm{NS}$ & $14.56 \pm 8.27 \mathrm{NS}$ & $17.84 \pm 12.86 \mathrm{NS}$ \\
\hline SEB2 & $23.88 \pm 10.67 \mathrm{ab}$ & $0.83 \pm 0.71 \mathrm{NS}$ & $0.83 \pm 0.35 \mathrm{NS}$ & $8.95 \pm 3.76 \mathrm{NS}$ & $9.84 \pm 6.20 \mathrm{NS}$ \\
\hline
\end{tabular}

${ }^{\mathrm{z}} \mathrm{W}=$ west Slovenia; WB = western border with Croatia; SW = southwest Slovenia; SE = southeast Slovenia; SEB = southeastern border with Croatia.

${ }^{\mathrm{y}}$ Different letters $(\mathrm{a}-\mathrm{c})$ within columns show statistically significant differences in each parameter among different genotype origin by Duncan test at $P \leq 0.05 ;$ NS $=$ not significant.

$\mathrm{FW}=$ fresh weight.

belonged to different phenolic groups: glycosides of quercetin and myricetin (Tables 7 and 10). The highest concentrations in the group of quercetin glycosides were of quercetin-3-rutinoside, between $19,474.40$ and $61,237.93 \mu \mathrm{g} \cdot \mathrm{g}^{-1} \mathrm{FW}$ and quercetindirhamnosyl hexoside, between 5019.96 and $28,376.09 \mu \mathrm{g} \cdot \mathrm{g}^{-1}$ $\mathrm{FW}$, but the values were not significantly different among genotypes from different sites of origin. The values of quercetin3-glucoside, between 1296.69 and $6130.90 \mu \mathrm{g} \cdot \mathrm{g}^{-1} \mathrm{FW}$ and quercetin-3-rhamnoside, between 49.56 and $303.76 \mu \mathrm{g} \cdot \mathrm{g}^{-1} \mathrm{FW}$, were much lower, and differences among genotypes from different sites of origin were significant. Laricitin-3-rutinoside, kaempferol-3-rutinoside, isorhamnetin-3-rutinoside, and neohesperidin were additionally analyzed (Tables 7 and 11). Values of neohesperidin and laricitin-3-rutinoside differed significantly among genotypes from different regions of origin.

Classifying the Genotypes. Principal component analysis was carried out to simplify the multivariate model based on analysis of anthocyanins and flavonols in cyclamen flowers and leaves. The first two principal components (Factor 1 and Factor 2) accounted for $64.7 \%$ (leaves) and $73.6 \%$ (flowers) of the total variance and were used to obtain a scatter plot (Figs. 5 and 6). Factor 1 represented $41.44 \%$ of the total variation in leaves and $38.55 \%$ in flowers and was associated mainly with the total flavonol content and some anthocyanins (mostly delphinidin and cyanidin derivatives in flowers) on discrimination of the species. Factor 2 accounted for $23.22 \%$ of the total variation in leaves and $35.05 \%$ in flowers and was mostly associated with the anthocyanin content in leaves (mainly malvinidin derivatives). In summary, the anthocyanin derivate contents varied with the origin of the cyclamen clones.

The tendency toward a grouping of the clones in accordance with flavonol and anthocyanin contents is graphically shown by the dendrogram (Figs. 7 and 8). There were three major groups formed by plants: with high (SE2, SEB1, and WB1), medium 


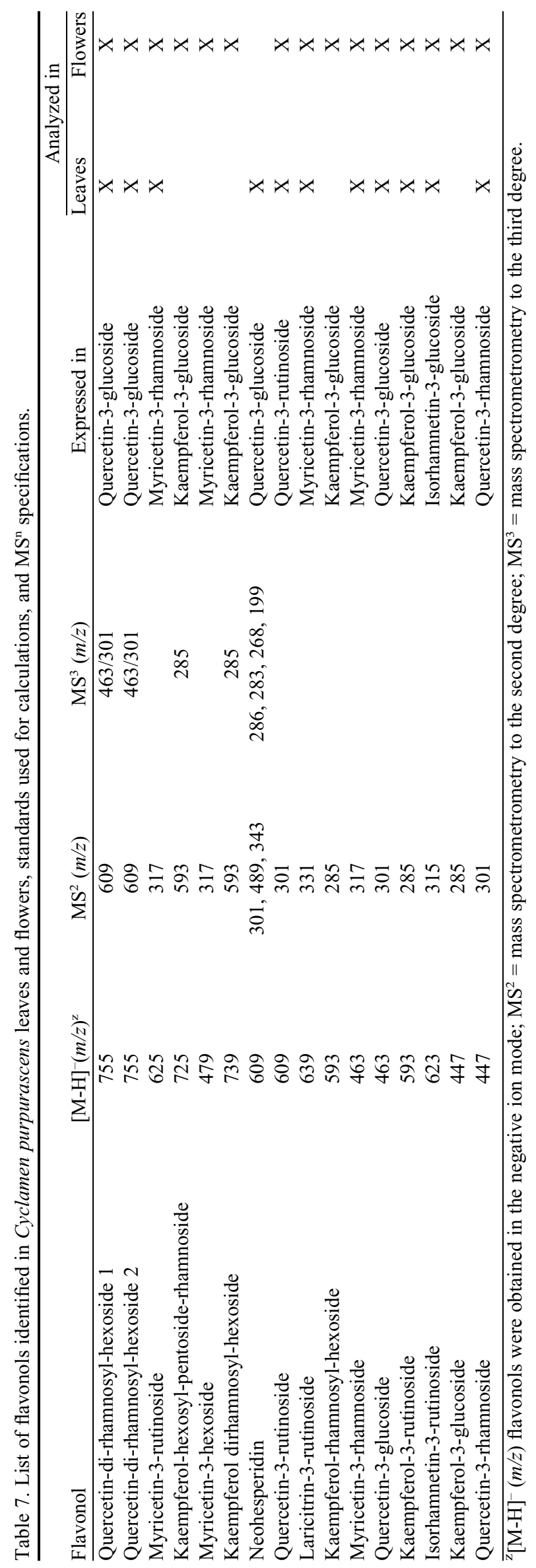

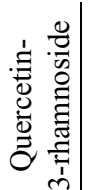

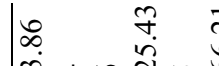

मे

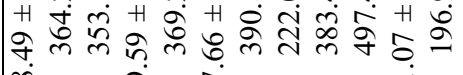

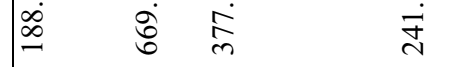

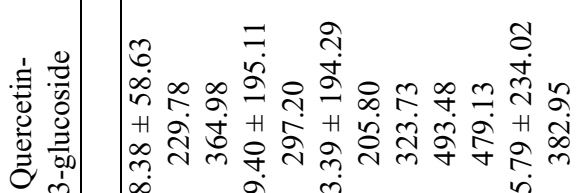
$\infty$ के ते 㝏

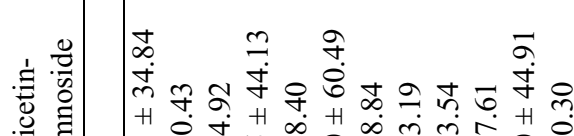

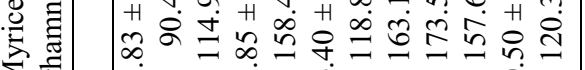

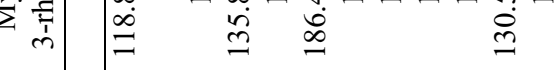

के

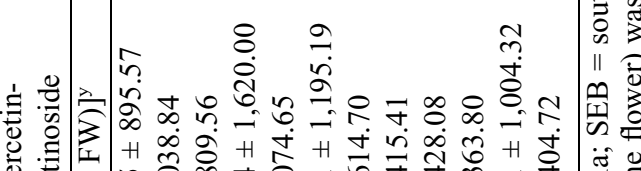

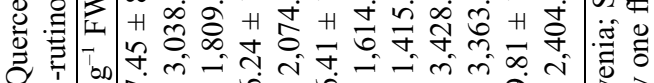

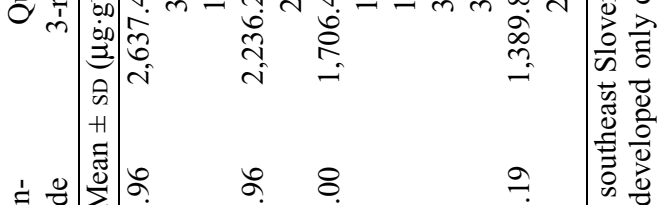

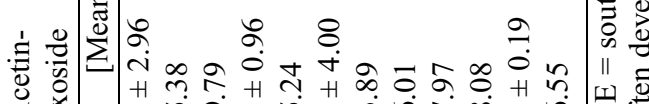

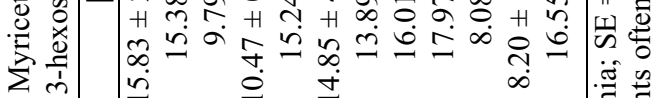

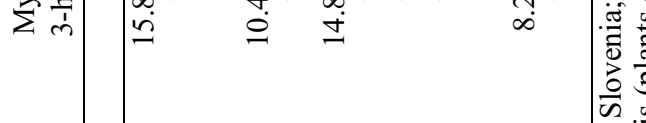

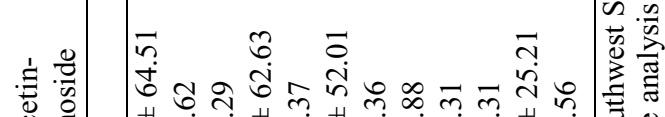

参.寻

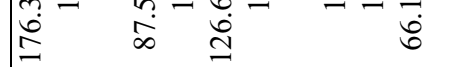

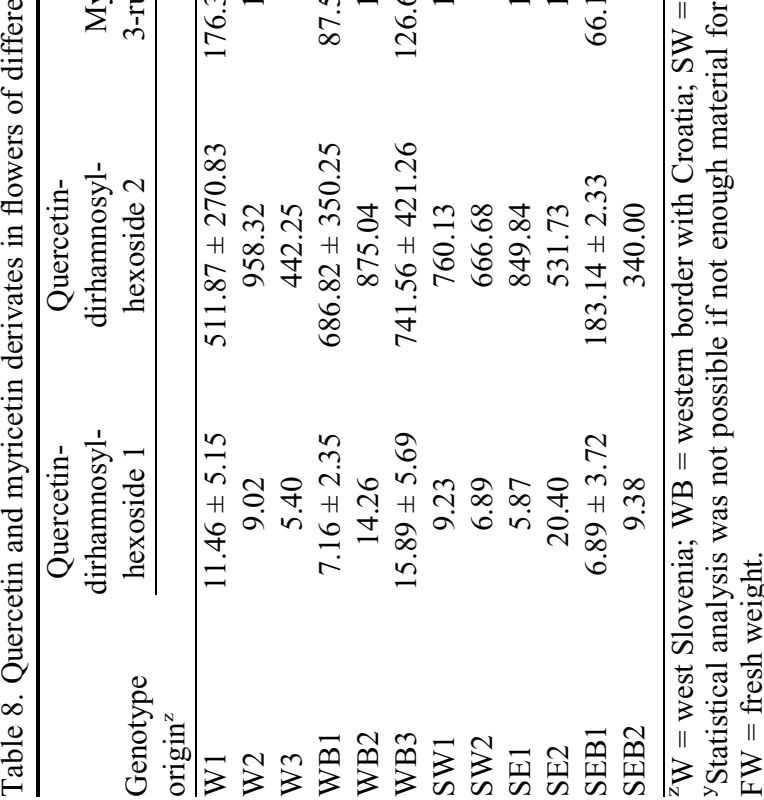




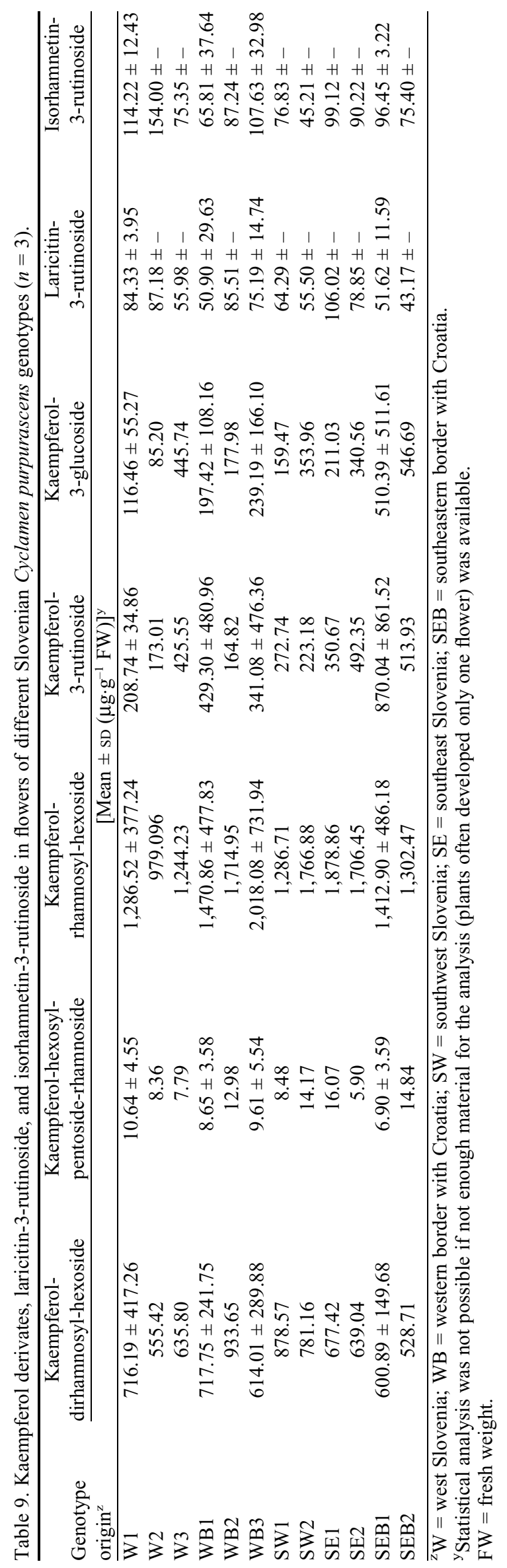

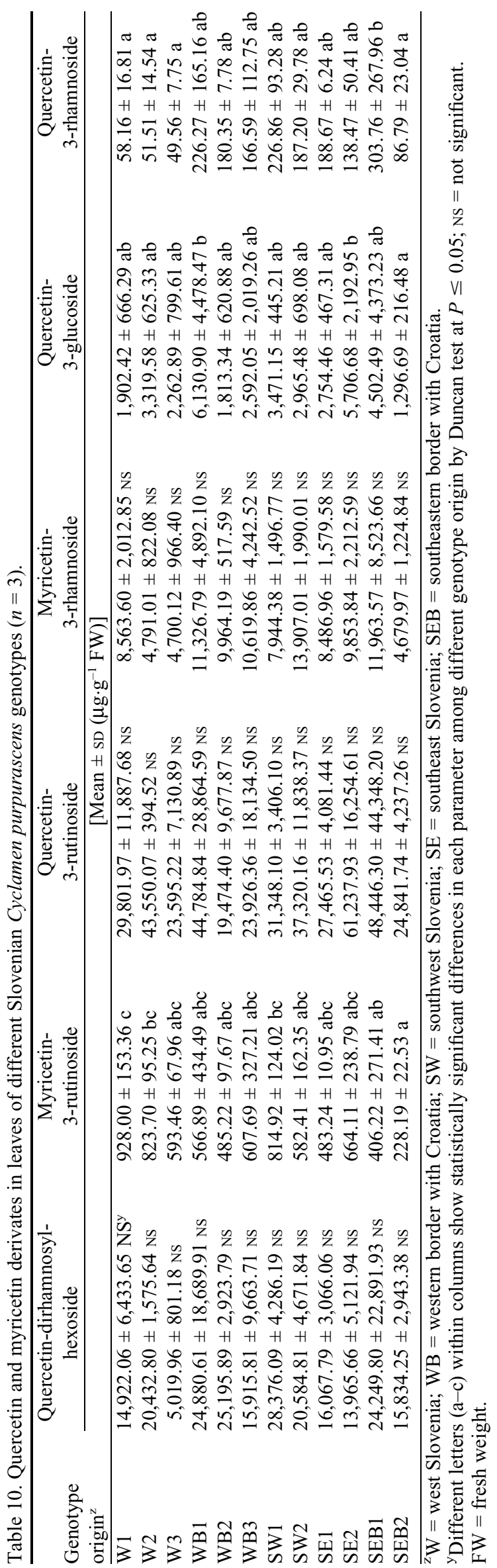


Table 11. Rutinoside derivates of laricitin, kaempferol, and isorhamnetin and neohesperidin in leaves of different Slovenian Cyclamen purpurascens genotypes $(n=3)$.

\begin{tabular}{|c|c|c|c|c|}
\hline \multirow[b]{2}{*}{ Genotype origin $^{z}$} & Neohesperidin & Laricitin-3-rutinoside & Kaempferol-3-rutinoside & Isorhamnetin-3-rutinoside \\
\hline & \multicolumn{4}{|c|}{$\left[\right.$ Mean \pm SD $\left.\left(\mu \mathrm{g} \cdot \mathrm{g}^{-1} \mathrm{FW}\right)\right]$} \\
\hline W1 & $501.80 \pm 433.83 \mathrm{a}^{\mathrm{y}}$ & $792.20 \pm 322.21 \mathrm{~b}$ & $66.87 \pm 40.57 \mathrm{NS}$ & $254.31 \pm 213.64 \mathrm{NS}$ \\
\hline W2 & $654.61 \pm 60.44 \mathrm{a}$ & $630.88 \pm 77.21 \mathrm{ab}$ & $42.46 \pm 14.98 \mathrm{NS}$ & $85.81 \pm 17.80 \mathrm{NS}$ \\
\hline W3 & $247.67 \pm 58.80 \mathrm{a}$ & $566.89 \pm 99.04 \mathrm{ab}$ & $33.21 \pm 11.59 \mathrm{NS}$ & $92.10 \pm 12.67 \mathrm{NS}$ \\
\hline WB1 & $2,935.42 \pm 2,076.26 \mathrm{~b}$ & $433.20 \pm 245.38 \mathrm{a}$ & $85.02 \pm 116.63 \mathrm{NS}$ & $212.73 \pm 293.95 \mathrm{NS}$ \\
\hline WB2 & $2,257.43 \pm 699.68 \mathrm{ab}$ & $377.83 \pm 12.04 \mathrm{a}$ & $14.85 \pm 7.54 \mathrm{NS}$ & $174.90 \pm 43.78 \mathrm{NS}$ \\
\hline WB3 & $1,521.99 \pm 1,090.02 \mathrm{ab}$ & $454.33 \pm 170.98 \mathrm{ab}$ & $39.34 \pm 30.84 \mathrm{NS}$ & $132.80 \pm 125.00 \mathrm{NS}$ \\
\hline SW1 & $2,812.58 \pm 597.46 \mathrm{~b}$ & $449.93 \pm 40.40 \mathrm{ab}$ & $89.26 \pm 19.65 \mathrm{NS}$ & $176.98 \pm 70.08 \mathrm{NS}$ \\
\hline SW2 & $2,268.18 \pm 213.42 \mathrm{ab}$ & $589.06 \pm 132.48 \mathrm{ab}$ & $80.56 \pm 23.84 \mathrm{NS}$ & $216.02 \pm 42.29 \mathrm{NS}$ \\
\hline SE1 & $2,198.07 \pm 254.95 \mathrm{ab}$ & $477.38 \pm 33.09 \mathrm{ab}$ & $48.61 \pm 12.21 \mathrm{NS}$ & $196.16 \pm 2.16 \mathrm{NS}$ \\
\hline SE2 & $561.51 \pm 179.23 \mathrm{a}$ & $450.68 \pm 177.86 \mathrm{ab}$ & $52.61 \pm 17.64 \mathrm{NS}$ & $57.95 \pm 19.24 \mathrm{NS}$ \\
\hline SEB1 & $2,182 \cdot 00 \pm 2,107.11 \mathrm{ab}$ & $479.31 \pm 223.87 \mathrm{ab}$ & $54.36 \pm 41.29 \mathrm{NS}$ & $211.69 \pm 151.33 \mathrm{NS}$ \\
\hline SEB2 & $679.18 \pm 257.86 \mathrm{a}$ & $317.76 \pm 38.42 \mathrm{a}$ & $78.58 \pm 14.98 \mathrm{NS}$ & $54.42 \pm 12.30 \mathrm{NS}$ \\
\hline
\end{tabular}

${ }^{\mathrm{z}} \mathrm{W}=$ west Slovenia; $\mathrm{WB}=$ western border with Croatia; $\mathrm{SW}=$ southwest Slovenia; $\mathrm{SE}=$ southeast Slovenia; SEB $=$ southeastern border with Croatia . ${ }^{\mathrm{y}}$ Different letters ( $\mathrm{a}$ and $\mathrm{b}$ ) within columns show statistically significant differences in each parameter among different genotype origin by Duncan test at $P \leq 0.05 ;$ NS $=$ not significant.

$\mathrm{FW}=$ fresh weight.

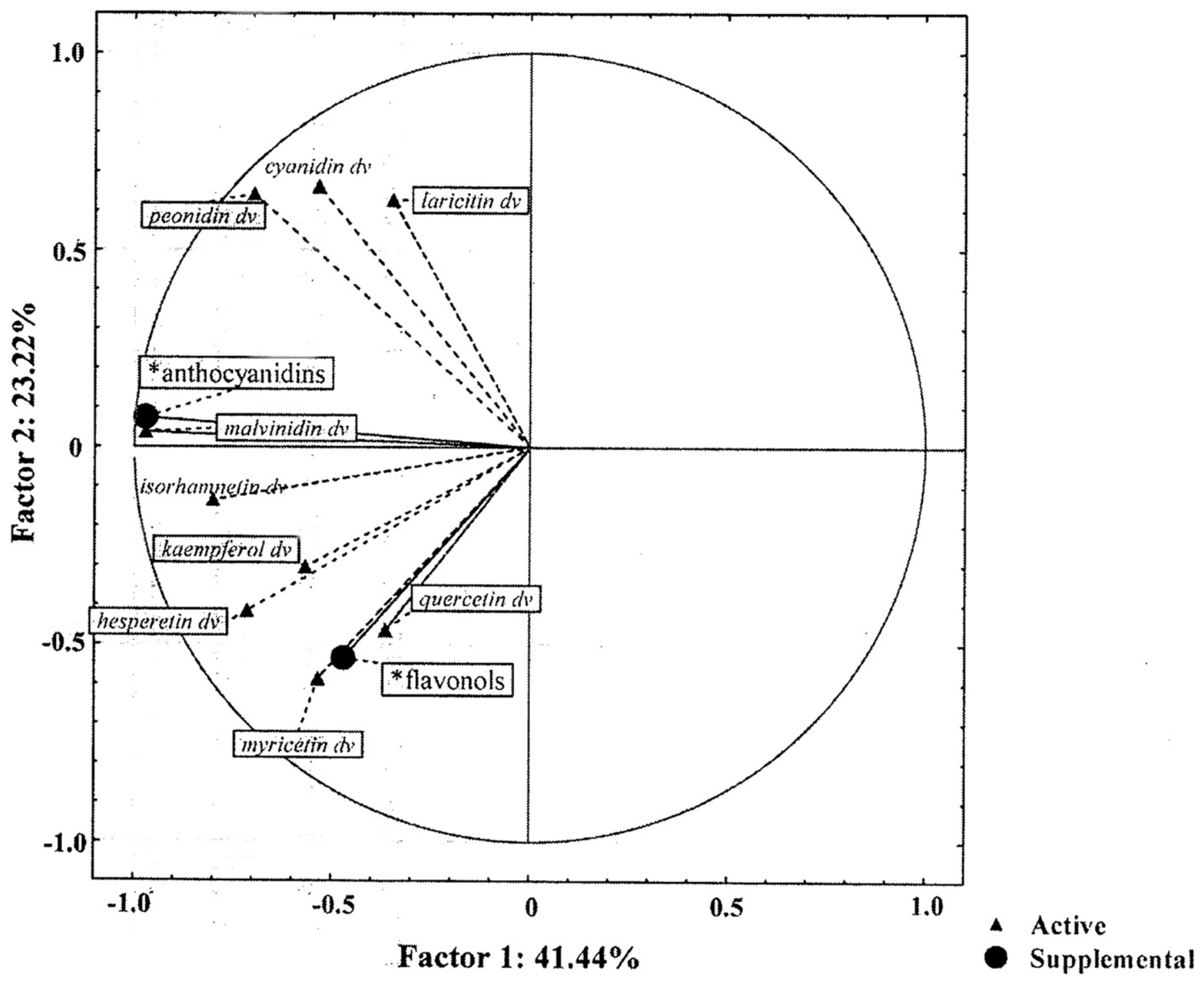

Fig. 5. Principal component analysis two-dimensional scatter plot based on the first two principal components (Factor 1 and Factor 2) generated for Cyclamen purpurascens clones and based on data of flavonol and anthocyanin derivative contents in leaves. 


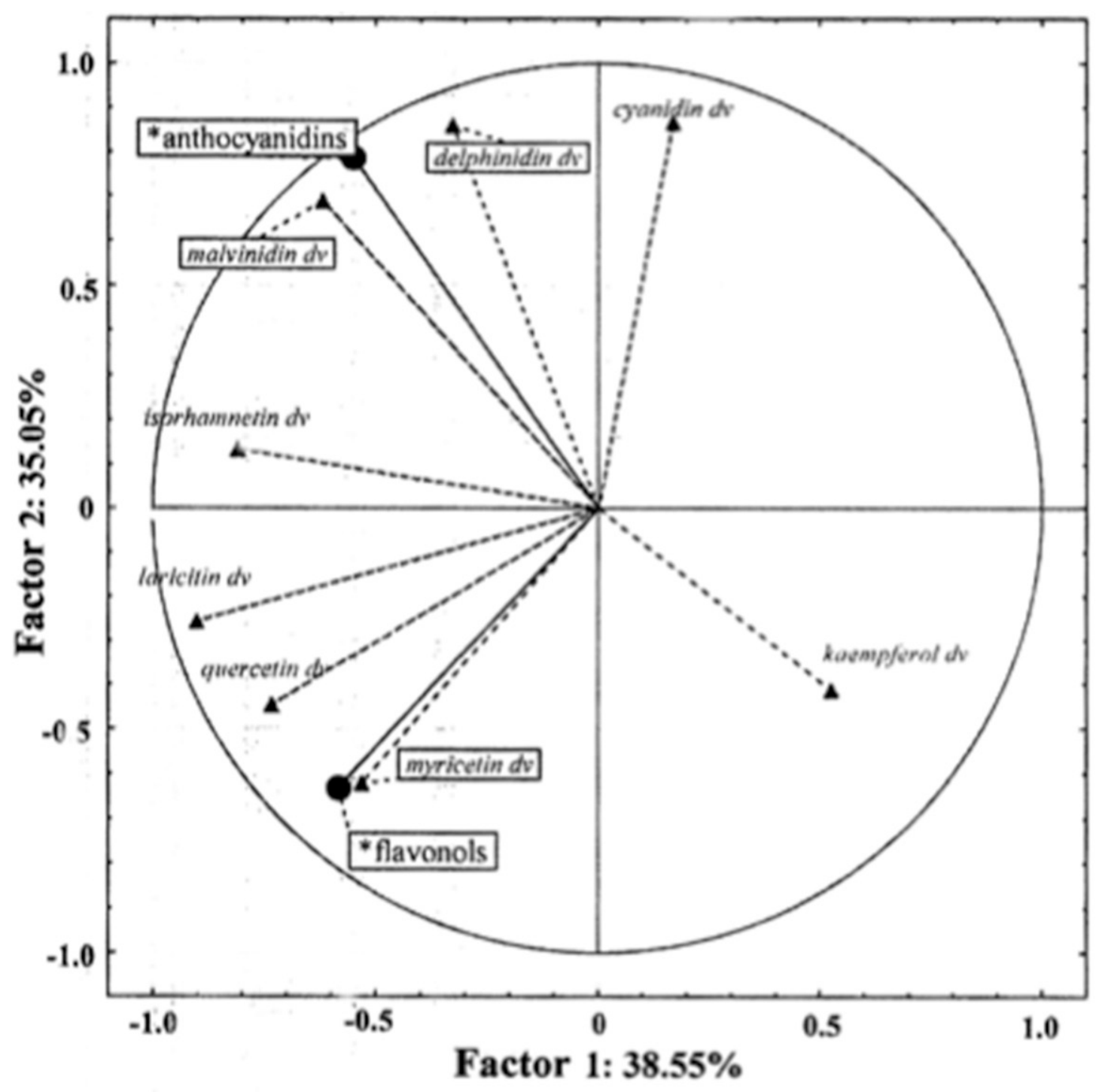

Active
- Supplemental

Fig. 6. Principal component analysis two-dimensional scatter plot based on the first two principal components (Factor 1 and Factor 2) generated for Cyclamen purpurascens clones and based on data of flavonol and anthocyanin derivative contents in flowers.

(W2, SW1, and SW2), and low (W1 and W3, WB2 and WB3, and SE1 and SEB2) content of the investigated compounds in leaves (Fig. 7). In relation to flowers, plants from SE2, SEB1, and WB1 localities had the highest content of tested phenolics and were markedly distinguished from the other localities (Fig. 8).

\section{Discussion}

Common cyclamens are very important ornamental plants in many countries of the Alpine, Dinarid, and Carpathian regions, in the past also in Slovenia (Bavcon, 2009). Today, they are particularly important for various breeding programs (Ishizaka et al., 2012; Osterc et al., 2014). The great value of common cyclamens compared with persian cyclamen is their ornamental leaves, their pleasant flower fragrances and the great range of flower colors (Bavcon, 2009; Moroe, 1991; Osterc et al., 2014; Takamura et al., 2005). Color measurements revealed that the studied genotypes developed flowers of various red colorations. $\mathrm{pH}$ measurements of the petal sap showed that flowers of all genotypes showed an acidic $\mathrm{pH}$ reaction. This suggests that the $\mathrm{pH}$ value in these genotypes is responsible for stabilizing red forms of anthocyanins (Glover, 2014). Detailed phenolic analysis of the studied genotypes of common cyclamen revealed that their flowers contain very different anthocyanins. Our results support the findings of some previous studies in relation to the presence of malvidin-3,5-diglucoside in specific cultivars of common cyclamen (Ishizaka et al., 2012; Takamura et al., 2005). Moreover, malvidin-3,5-diglucoside and delphinidin-3glucoside were even found to be the dominant anthocyanins in flowers of common cyclamen. Flowers also contained delphinidin-3,5-diglucoside, but in different concentrations depending on the genotype. However, flowers of our common cyclamen genotypes did not contain peonidin-3-neohesperidoside, as already reported for flowers of persian cyclamen (Webby and Boase, 1999). 


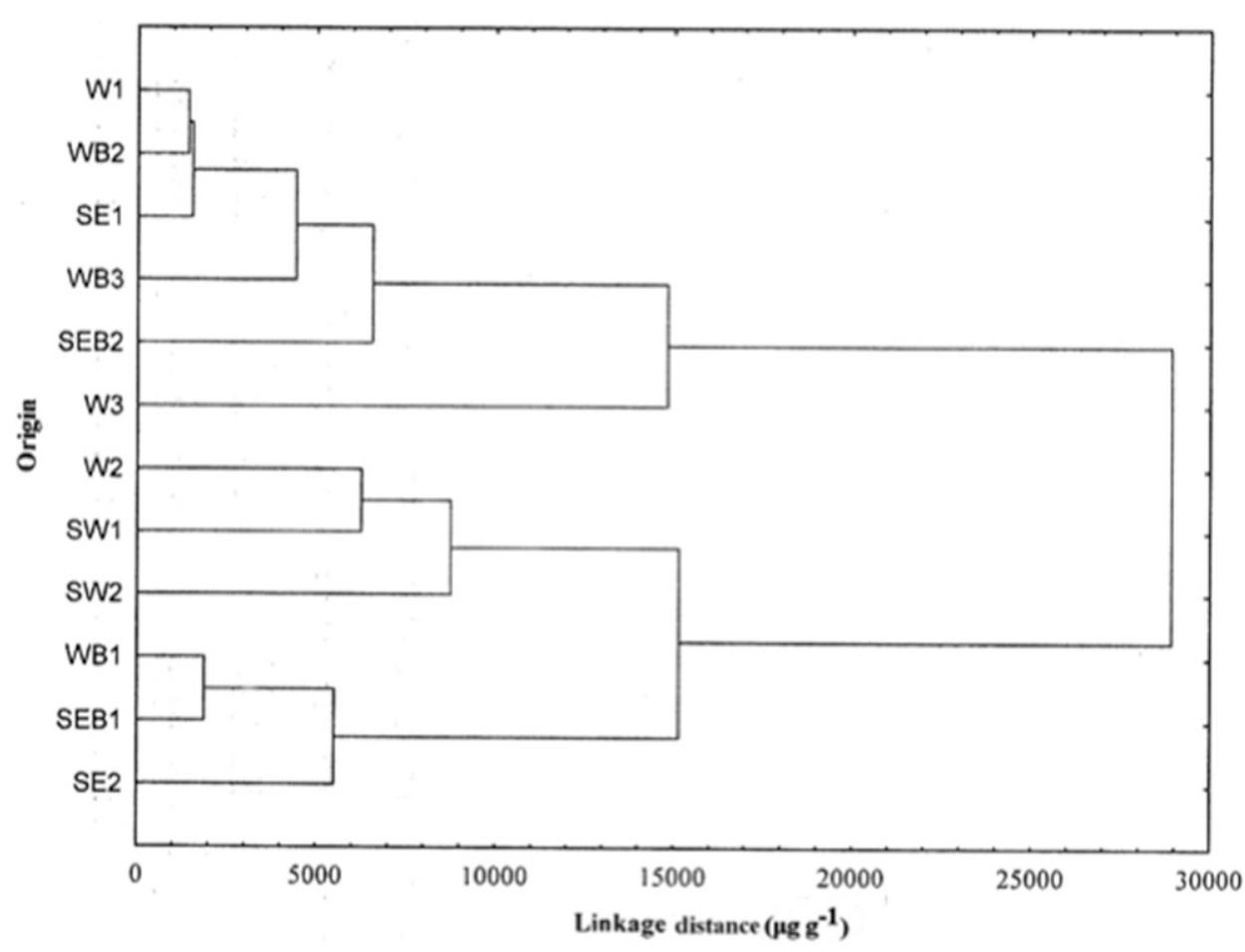

Fig. 7. Dendrogram of the results of cluster analysis using flavonol and anthocyanin contents as variables in analyzed Cyclamen purpurascens leaves.

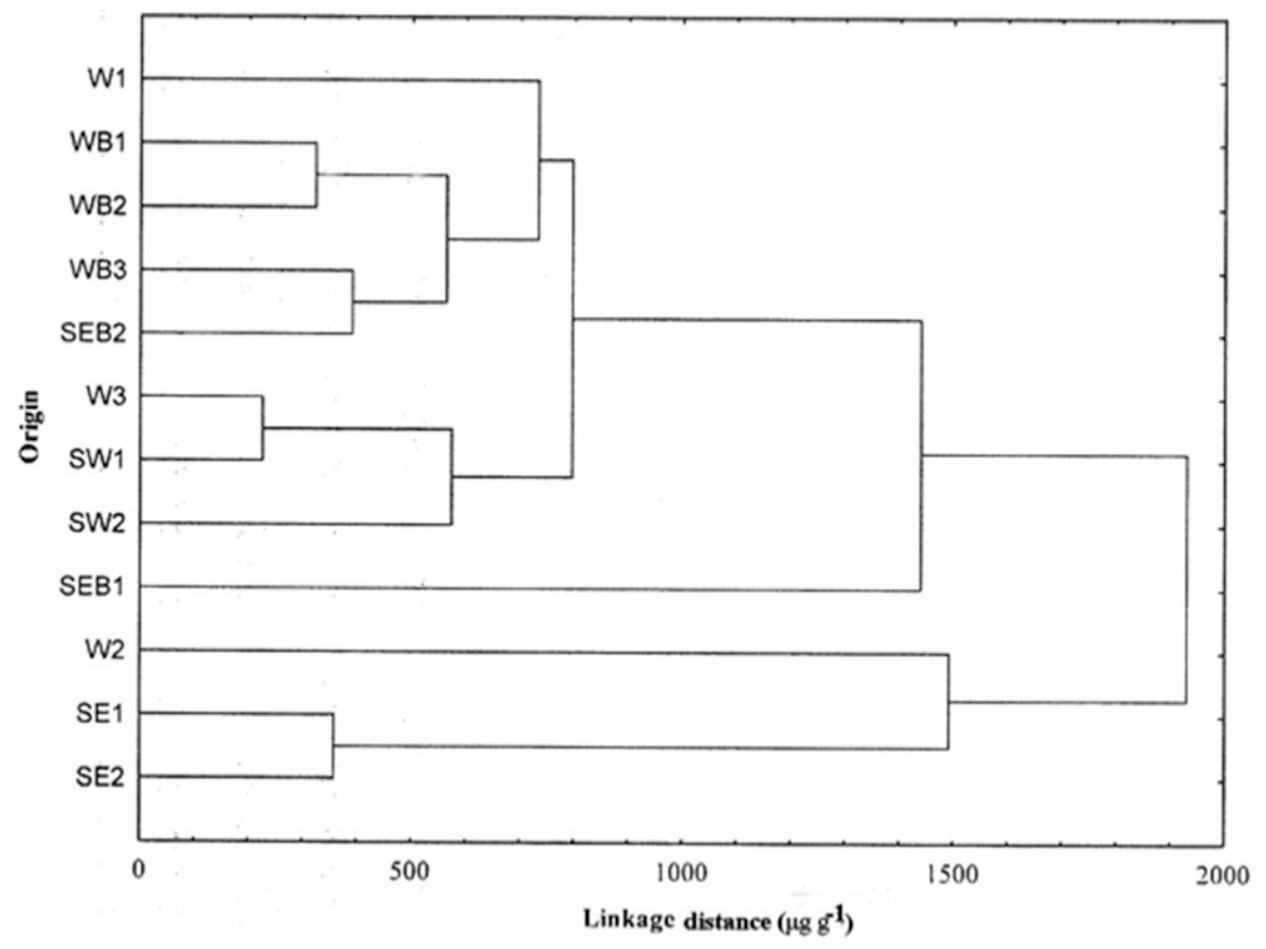

Fig. 8. Dendrogram of the results of cluster analysis using flavonol and anthocyanin contents as variables in analyzed Cyclamen purpurascens flowers.

Kondo et al. (2009) described the presence of delphinidin3,5-diglucoside in one plant of second generation mutants $\left(\mathrm{M}_{2}\right)$ obtained after self-pollination of mutants of the first generation $\left(\mathrm{M}_{1}\right)$, whereby the mutants resulted from irradiation of some interspecific hybrids between persian and common cyclamen species. Our results showed that delphinidin-3,5-diglucoside is actually present naturally in common cyclamen genotypes. These genotypes are, therefore, potentially very useful for practice because specific differences in plant metabolism acquired with mutations or similar methods can be lost over the course of the following years. Differences resulting in the formation of specific compounds found in these Slovene genotypes are constant because we identified them in plants that had grown in the same place for several years after collection in situ. Takamura et al. (2005) reported that all F1 progenies of interspecific hybrids between persian cyclamen cultivars and cultivars of common cyclamen contained various 3,5-diglucosides as the main pigments in their petals, including malvidin-3,5diglucoside, peonidin 3,5-diglucoside, and cyanidin-3,5-diglucoside, but they could not determine delphinidin-3,5diglucoside in their hybrids. However, we found the latter compound in the common cyclamen genotypes in the present study.

The wide palette of anthocyanins measured in leaves also resulted in different leaf colors in common cyclamen (the presence of anthocyanins from the delphinidin group resulted in a blue shade on the lower part of the leaf lamina) compared with persian cyclamen, as already reported (Osterc et al., 2014). Leaves of the analyzed cyclamens also contained cyanidin-3-neohesperidoside and peonidin 3-neohesperidoside. Peonidin 3-neohesperidoside was first determined in flowers of persian cyclamen (Webby and Boase, 1999), but common cyclamens evidently contain this peonidin glycoside in leaves, as already reported in our previous study (Osterc et al., 2014). Webby and Boase (1999) reported cyanidin-3-neohesperidoside to be present in traces in flowers of persian cyclamen. Some anthocyanins are responsible for certain color shades in leaves, again as already reported (Ishizaka et al., 2012; Kondo et al., 2009; Takamura et al., 2005). Kondo et al. (2009) reported that one mutant of the $\mathrm{M}_{2}$ generation developed red-purple flowers and that delphinidin-3,5-diglucoside was responsible for this color shade.

The development of anthocyanins is also closely connected with environmental conditions in particular years, which is defined by some authors as environmental determination of 
color (Manetas, 2006). The activity of key enzymes involved in the phenol (especially anthocyanin and flavonol) metabolism is known to be stronger under conditions of high irradiance and also high temperatures, or greater differences between the highest and lowest temperatures. Stronger accumulation of anthocyanins and flavonols, therefore, occurs under such conditions (Feng et al., 2013; Li et al., 2013). Our plants were exposed to the higher temperatures during their annual development (especially between September and November) in 2014. Direct exposure of plants to higher temperatures and higher sunlight is very important for the anthocyanin and flavonol picture (Cooney et al., 2015).

On the other hand, based on detailed statistical analysis (cluster analysis), it can be summarized that not all localities from the same region have genotypes with similar leaf and flower characteristics. Each genotype is evidently a result of the environmental and edaphic conditions (annual disposition of temperature and precipitation, structure of the soil, etc.) that they are adapted to in the environment they evolved in at the point of collection. Genotypes from the west border with Italy are typical examples. We sampled three different genotypes from this district that were only few kilometers away from each other. They gave totally different cluster pictures for flower color. The first (W1), sampled more to the north (much more annual precipitations, colder area), was not similar to the pictures of either of the other two genotypes. The second (W2) and third (W3), based on their cluster picture, were much more similar to genotypes originating in a more horizontal line, more to the east. The W2 genotype, therefore, is more similar in its flower pattern to the patterns of SE genotypes (less annual precipitations and warmer areas) and the W3 genotype with the patterns of SW genotypes (middle annual precipitations and warmer areas, but not as much as SE areas). The partition of genotypes was a little bit different in leaf patterns. Genotypes from the west differed strongly among themselves and formed three different groups. This may be evidence that the environmental characteristics of the locality of origin affect the leaf and floral characteristics of genotypes even more strongly than the conditions of the place in which the genotypes are grown after replanting.

\section{Conclusions}

It was demonstrated that common cyclamen is able to form anthocyanins from the delphinidin group (delphinidin-3-glucoside, delphinidin-3,5-diglucoside, and delphinidine-3-rutinoside) naturally. These plants are, therefore, potentially very interesting as horticultural plants. These differences in leaf and floral characteristics are likely the result of the evolution of the specific genotypes to the environmental conditions of the locality of origin as these differences can be seen after replanting the plants in a new location with different environmental conditions.

\section{Literature Cited}

Bavcon, J. 2009. Common cyclamen (Cyclamen purpurascens Mill.) and its diversity in Slovenia. 1st ed. Biotechnical Faculty, Dept. Biol., Botanic Garden, Ljubljana, Slovenia.

Bavcon, J. 2013. Naše rastline. 1st ed. Mohorjeva Celovec, Ljubljana, Slovenia.
Bavcon, J. and B. Ravnjak. 2015. Population occurrence of white flowered varieties of some plant species in the submediterranean area of Slovenia, p. 27. In: Ž. Fišer Pečnikar and M. Lužnik (eds.). Intl. Wkshp. Biodiversity Mediterranean Basin. Up Famnit Publ., Koper, Slovenia.

Cooney, L.J., H.M. Shaefer, B.A. Logan, B. Cox, and K.S. Gould. 2015. Functional significance of anthocyanins in peduncles in Sambucus nigra. Environ. Expt. Bot. 119:18-26.

Feng, F., M. Li, F. Ma, and L. Cheng. 2013. Phenylpropanoid metabolites and expression of key genes involved in anthocyanin biosynthesis in the shaded peel of apple fruit in response to sun exposure. Plant Physiol. Biochem. 69:54-61.

Glover, B. 2014. Understanding flowers and flowering. 2nd ed. Univ. Press, Oxford, UK.

Grey-Wilson, C. 1988. The genus Cyclamen. Christopher Helm/ Timber, London, UK.

Grey-Wilson, C. 2002. Cyclamen: A guide for gardeners, horticulturists and botanists. Batsford, London, UK.

Grimshaw, J. 1992. Red pigmentation in cyclamen leaves. Cyclamen $16: 23-26$.

Hildebrand, F. 1898. The genus Cyclamen L. a systematic and biological monograph. Cyclamen Soc., London, UK.

Ishizaka, H., H. Yamada, and K. Sasaki. 2002. Volatile compounds in the flowers of Cyclamen persicum, Cyclamen purpurascens and their hybrids. Scientia Hort. 94:125-135.

Ishizaka, H., E. Kondo, and N. Kameari. 2012. Production of novel flower color mutants from the fragrant cyclamen (Cyclamen persicum $\times C$. purpurascens) by ion-beam irradiation. Plant Biotechnol. 29:201-208.

Kondo, E., M. Nakayama, N. Kameari, N. Tanikawa, Y. Morita, Y. Akita, Y. Hase, A. Tanaka, and H. Ishizaka. 2009. Red-purple flower due to delphinidin-3,5-diglucoside, a novel pigment for Cyclamen spp., generated by ion-beam irradiation. Plant Biotechnol. 26:565-569.

Li, P., F. Ma, and L. Cheng. 2013. Primary and secondary metabolism in the sun-exposed peel and the shaded fruit of apple fruit. Physiol. Plant. 148:9-24.

Manetas, Y. 2006. Why some leaves are anthocyanic and why most anthocyanic leaves are red? Flora 201:163-177.

Mathew, B. 2013. Genus Cyclamen in science, cultivation, art and culture. Kew Royal Botanic Gardens/Cyclamen Soc., London, UK.

Moroe, T. 1991. Kaori no hyakka. Nihon koryo kyokai. Asakura Shoten, Tokyo, Japan.

Osterc, G., V. Cunja, M. Mikulic-Petkovsek, V. Schmitzer, F. Stampar, and J. Bavcon. 2014. Foliage identification of different autochthonous common cyclamen genotypes (Cyclamen purpurascens Mill.) using various biochemical parameters. Scientia Hort. 173:37-44.

Statistical Office of the Republic of Slovenia. 2016. Podnebni kazalniki. 7 Apr. 2016. <http://pxweb.stat.si/pxweb/Database/ Okolje/01_ozemlje_podnebje/10_01561_podnebni_kazalniki/10_ 01561_podnebni_kazalniki.asp/>.

Slovák, M., J. Kučera, P. Turis, and J. Zozomova-Lihova. 2012. Multiple glacial refugia and postglacial colonization routes inferred for a woodland geophyte, Cyclamen purpurascens: Patterns concordant with the Pleistocene history of broadleaved and coniferous tree species. Biol. J. Linn. Soc. Lond. 105:741-760.

Takamura, T., M. Nakayama, and H. Ishizaka. 2005. Inheritance of flower pigment in crosses between cyclamen cultivars and Cyclamen purpurascens. Acta Hort. 673:437-441.

Wang, S.Y., W. Zheng, and G.J. Galletta. 2002. Cultural system affects fruit quality and antioxidant capacity in strawberries. J. Agr. Food Chem. 50:6534-6542.

Webby, R.F. and M.R. Boase. 1999. Peonidin-3-o-neohesperidoside and other flavonoids from Cyclamen persicum petals. Phytochemistry 52:939-941. 